\title{
Perioperative risk of complete heart block in patients with bifascicular block and prolonged PR interval
}

\author{
FRANK L MIKELL, E KENNETH WEIR, AND ELLIOT CHESLER \\ From the Department of Medicine, Division of Cardiology, Veterans Administration Medical Center, \\ and the University of Minnesota, Minneapolis, Minnesota, US.4
}

\begin{abstract}
Because there is a paucity of information on the perioperative risk of developing complete heart block among patients with bifascicular block (either right bundle branch block and left anterior hemiblock or left bundle branch block) and a long PR interval on the surface electrocardiogram, we undertook an analysis of 76 such patients. Twenty-three patients had right bundle branch block and left axis deviation with a long PR interval and 53 had left bundle branch block with a long PR interval. Thirty patients had 37 general anaesthetics, 23 had 32 spinal anaesthetics, and 50 had 64 local anaesthetics or endoscopic procedures. No patient developed complete heart block. Four patients developed sinus bradycardia during general anaesthetics, responsive to atropine or isoproternol. Similarly, none of the 23 such patients in the literature reviewed had developed complete heart block. Because placement of temporary pacemakers is not without risk, we conclude that prophylactic pacing is not necessary in asymptomatic patients with bifascicular block even in the presence of a long PR interval. Since we did not study patients with recent syncope or myocardial infarction, caution should be exercised in applying these results to such patients.
\end{abstract}

Cardiologists are frequently asked to advise upon the necessity for perioperative prophylactic pacemaking in patients whose resting surface electrocardiograms show bifascicular block and prolongation of the PR interval. Currently there is little information available on the risk of perioperative complete heart block in patients with left bundle branch block (LBBB) and prolonged PR interval and reports of right bundle branch block and left anterior hemiblock (RBBB-LAHB) have included only few patients with PR prolongaltion..$^{1-3} \mathrm{~A}$ recent report has continued to recommend pacemaker placement in the latter group. ${ }^{2}$ Because the value of prophylactic temporary ventricular pacing is uncertain in such patients, we have analysed their perioperative risk of developing complete heart block.

Address for reprint requests: Dr $\mathbf{E}$ Kenneth Weir, Division of Cardiology, Department of Internal Medicine, Veterans Administration Medical Centre, Minneapolis, Minnesota 55417, USA.

\section{Methods}

A retrospective analysis was made of the medical records of all patients at the Veterans Administration Medical Center, Minneapolis, whose resting surface electrocardiograms showed a prolonged PR interval $(\geqslant 0.20 \mathrm{~s})$ associated with either RBBB and LAHB (group 1) or LBBB (group 2), between the years 1968-78 inclusive. Left anterior hemiblock was defined as a mean frontal plane QRS axis more negative than -30 degrees in the absence of an inferior myocardial infarction or emphysema. The records of 76 patients (23 in group 1, 53 in group 2) who had undergone a surgical or diagnostic procedure under general, spinal, or local anaesthesia were identified. All 76 patients were men. None of the patients had syncope in the year before surgery, or a myocardial infarction during the preceding three months Twenty-nine patients had stable angina pectoris at the time of operation and 22 patients had 
historical evidence of myocardial infarction. Thirty-six patients were receiving digitalis compounds but none were thought to have digitalis intoxication. Review of previous electrocardiograms available in 42 patients showed the electrocardiographic findings to have been present for a range of one month to nine years $(2 \cdot 6 \pm 0 \cdot 8$ years, mean \pm SEM).

Operations under general anaesthesia included abdominal aortic aneurysmectomies, total hip replacements, aortic or mitral valve replacements, thoracotomies, colectomies, hernia repairs, nephrectomy, cholescystectomy, vagotomy and pyloroplasty, and exploratory laparotomies. Procedures done under spinal anaesthesia included transurethral prostatic resections, hernia repairs, resection of ileum, varicose vein stripping, colostomies, and leg amputations. Local anaesthetics were used for skin excisions, circumcisions, cataract extractions, antrostomy and tympanoplasty, and metatarsal amputation. In addition, diagnostic procedures such as endoscopies and thoracenteses with biopsies were noted in these patients. A detailed review was made of the anaesthetic and surgical records including the postoperative period. All patients undergoing general or spinal anaesthesia

Table 1 Electrocardiographic features of patients with bifascicular block and $P R$ prolongation

\begin{tabular}{llllll}
\hline & $\begin{array}{l}\text { Age } \\
(y r)\end{array}$ & $\begin{array}{l}\text { HR } \\
\text { beats/ } \\
\min \end{array}$ & $\begin{array}{l}P R \\
m s\end{array}$ & $\begin{array}{l}\text { QRS } \\
m s\end{array}$ & $\begin{array}{l}\text { QRS axis } \\
\text { degrees }\end{array}$ \\
\hline $\begin{array}{l}\text { Group 1 (RBBB- } \\
\begin{array}{l}\text { LAHB) } \\
\text { (n=23) }\end{array}\end{array}$ & $72 \pm 2$ & $74 \pm 2$ & $215 \pm 3$ & $142 \pm 2$ & $-63 \pm 5$ \\
$\begin{array}{l}\text { Group 2 (LBBB) } \\
\text { (n=53) }\end{array}$ & $66 \pm 2$ & $76 \pm 2$ & $228 \pm 3$ & $142 \pm 2$ & $\begin{array}{l}\text { LAD/ } \\
\text { Others/ }+29 \pm 3\end{array}$ \\
\hline
\end{tabular}

Values are mean \pm SEM

Table 2 Summary of reports on operative ri.k of bifascicular block and $P R$ prolongation

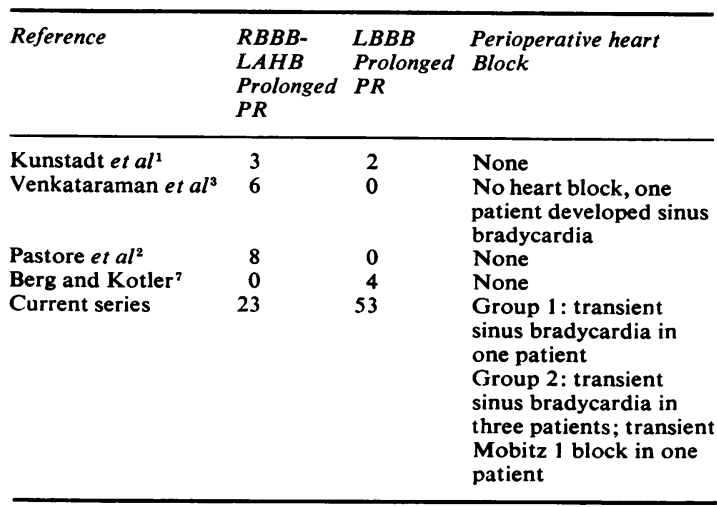

had single lead electrocardiographic monitoring during the procedure. Complications were noted, with special attention given to any alterations in heart rate or blood pressure. Postoperative electrocardiograms were reviewed and there were no significant differences from preoperative tracings in any of the patients. The patients' subsequent course and longterm follow-up were recorded.

\section{Results}

There were 23 patients in group 1 (RBBB, LAHB and prolonged PR); age range 47 to 87 years. Electrocardiographic measurements from the patients are listed in table 1. Eight patients had a total of 11 general anaesthetics, nine patients had 12 spinal anaesthetics, and 14 patients had 17 local anaesthetics or procedures. No patient required pacing in the perioperative period. One developed sinus bradycardia during general anaesthesia which was treated with atropine. Ten patients are known to be alive $4 \cdot 3 \pm 1 \cdot 0$ (mean \pm SEM) years after surgery, and on review of the records of these patients only one has required a permanent pacemaker. Thirteen have died or not attended a clinic during the last year. During a mean period of follow-up of $2.3 \pm 0.6$ years none of this latter group of patients was paced.

There were 53 patients in group 2 (LBBB and prolonged PR); age range 41 to 90 years. Electrocardiographic measurements are listed in table 1. Twenty-three of these patients had left axis deviation (mean frontal QRS axis $-45 \pm 3$ degrees) while 30 had normal QRS axis (mean frontal QRS axis $+29 \pm 5$ degrees). Twenty-two patients had a total of 26 general anaesthetics, 14 had 20 spinal anaesthetics, and 36 had 47 local anaesthetics or procedures. A prophylactic pacemaker was inserted in three patients before operation under general anaesthesia, but none of them had a bradycardia requiring the use of the pacemaker. None of the other patients required placement of a pacemaker in the perioperative period but three undergoing general anaesthesia had sinus bradycardia which required treatment with atropine or isoprenaline. Results were similar for patients with normal QRS axis or left axis deviation, although all three patients with sinus bradycardia during general anaesthesia had left axis deviation. One hour after local anaesthesia, one patient developed Mobitz type 1 second-degree heart block which resolved spontaneously. Twelve patients in group 2 are known to be alive $2 \cdot 4 \pm 0 \cdot 7$ years after surgery and none has required permanent pacing. The remaining 41 have died or not attended a clinic 
during the last year. During $1 \cdot 5 \pm 0 \cdot 3$ years of follow-up, four of these patients required permanent pacing.

\section{Discussion}

Patients with chronic bifascicular block are at risk of developing complete heart block even in the absence of the stress of surgical intervention. ${ }^{4-6}$ Consequently, several authors ${ }^{1-3}$ have examined the effects of operation on the development of complete heart block in patients with right bundle branch block and left anterior or posterior hemiblock. However, these reports include only a few patients who have prolongation of the PR interval on the surface electrocardiogram in addition to bifascicular block (table 2). Because of the paucity of information, the most recent report continued to recommend prophylactic pacing for the patients with prolonged PR intervals. ${ }^{2}$ In addition, we are unaware of any studies which have analysed the operative risk of large numbers of patients with left bundle branch block and PR prolongation (table 2). ${ }^{17}$

The prolongation of the PR interval on the surface electrocardiogram in both these types of bifascicular block has been shown to be the result of impaired conduction through either the atrioventricular node or remaining fascicle or both. ${ }^{8}$ While the risk of developing intraoperative complete heart block might depend on the site of delayed atrioventricular conduction, none of our patients had electrophysiological evaluation of the site of PR prolongation. However, previous studies have shown a high frequency of atrioventricular conduction prolongation in patients with RBBB and left axis deviation ${ }^{89}$ as well as left bundle branch block. ${ }^{9}$ Moreover, prolongation of the PR interval in patients with LBBB increases the risk of developing complete heart block. ${ }^{6}$ While transient complete heart block in the perioperative period has only been reported once in a total of 136 patients with bifascicular block, ${ }^{1-3} 7$ the additional risk produced by prolongation of the PR interval on the surface electrocardiogram and the need for perioperative prophylactic pacing during the stress of operation in these patients remains uncertain.

This study was undertaken to examine the need for perioperative prophylactic pacing in patients with bifascicular block and a prolonged PR interval on the surface electrocardiogram. The present series, combined with data from other studies (table 2), indicates that 99 patients with bifascicular block and PR prolongation underwent a variety of operations and diagnostic procedures $\overrightarrow{\vec{\rho}}$ including those with general, spinal, and local $\overline{0}$ anaesthesia withouit developing complete heart $\frac{}{\partial}$ block. The occurrence of one episode of transient $\overline{\frac{\rho}{7}}$ complete heart block in a patient with RBBB- $\mathbb{\Phi}$ LAHB without prolonged $\mathbf{P R},{ }^{2}$ and several instances of sinus bradycardia, however, stress the 2 importance of careful perioperative electrocardiographic monitoring. In addition, it should be noted that none of our patients had recent syncope or myocardial infarction.

Although left axis deviation associated with left bundle branch block may be more strongly associated with cardiac disease than left bundle branch block with a normal QRS axis, ${ }^{8}$ the influence of left axis deviation on the risk for developing complete heart block is not clear. In our $\vec{c}$ patients with left bundle branch block, the presence of left axis deviation did not appear to confer a risk for the development of perioperative heart block. However, it is interesting that all $\vec{\oplus}$ three patients with left bundle branch block and $\stackrel{\infty}{\rightarrow}$ long PR interval who had intraoperative sinus bradycardia requiring treatment had left axis deviation.

Thirty-six patients (nine with RBBB-LAHB, 27 with LBBB) in our series were treated with digitalis compounds in the perioperative period, although digitalis intoxication was not suspected in any. None of these patients had complete heart block during surgery, although the patient who developed transient second-degree Mobitz 1 block one hour after local anaesthetic was receiving digoxin.

The data presented here indicate that PR prolongation on the surface electrocardiogram associated with bifascicular block (either right bundle branch block and left anterior hemiblock or left bundle branch block) does not justify routine 을 preoperative placement of prophylactic temporary pacemakers. Temporary pacemakers may cause dysrhythmias,complete heart block, or ventricular $N$ perforation, either at the time the pacing wire is inserted or in the event that it becomes displaced $N$ subsequently. The risk of perioperative complete $\underset{\omega}{N}$ heart block or other advanced atrioventricular $\bar{O}$ block in these patients appears to be low. How- 6 ever, we did not study patients with recent syncope $\mathbb{D}$ or myocardial infarction and this conclusion may $\stackrel{\mathscr{f}}{\rightarrow}$ not be valid in these patients. We continue to re- 0 commend temporary pacemakers for such patients during surgery. The occurrence of sinus bradycardia requiring treatment with atropine or iso- $\stackrel{\mathbb{Q}}{\varrho}$ prenaline, as well as the need for caution, makes ECG monitoring throughout the perioperative 
period mandatory in patients with these conduction abnormalities.

\section{References}

1 Kunstadt D, Punja M, Cagin N, Fernandez P, Levitt B, Yuceoglu YZ. Bifascicular block: a clinical electrophysiologic study. Am Heart J 1973; 86:173-81.

2 Pastore JO, Yurchak PM, Janis KM, Murphy JD, Zir LM. The risk of advanced heart block in surgical patients with right bundle branch block and left axis deviation. Circulation 1978; 57:67780.

3 Venkataraman K, Madias JE, Hood WD. Indications for prophylactic preoperative insertion of pacemakers in patients with right bundle branch block and left anterior hemiblock. Chest 1975; 68:501-6.

4 Kulbertus HE. The magnitude of risk of develop- ing complete heart block in patients with LADRBBB. Am Heart J 1973; 86:278-9.

5 Scanlon PJ, Pryor R, Blount SG. Right bundle branch block associated with left superior or inferior intraventricular block: clinical setting, prognosis, and relation to complete heart block. Circulation 1970; 42:1123-33.

6 Wiberg TA, Richman HG, Gobel FL. The significance and prognosis of chronic bifascicular block. Chest 1977; 71:329-34.

7 Berg GR, Kotler MN. The significance of bilateral bundle branch block in the preoperative patient. Chest 1971; 59:62-7.

8 Narula OS, Samet P. Right bundle branch block with normal, left or right axis deviation. Analysis of His bundle recordings. Am J Med 1971; 51: $432-55$.

9 McAnulty JH, Rahimtoola SH, Murphy ES et al. A prospective study of sudden death in "highrisk" bundle branch block. $N$ Engl J Med 1978; 299:209-15. 